W stużbie tradycji i odnowy liturgicznej. 50 lat Instytutu Liturgicznego w Krakowie (1968-2018), red. P. Nowakowski, J. Mieczkowski, Kraków 2019, s. 319-331.

ISBN 978-83-7438-849-8 (wersja drukowana), ISBN 978-83-7438-850-4 (wersja online) DOI:http://dx.doi.org/10.15633/9788374388504.24

Avhustyn Solanskyy

Greckokatolicka Akademia Teologiczna be. Teodora Romży w Użgorodzie,

UKRAINA

\title{
Il rinnovamento della propria tradizione liturgica del Eparchia greco cattolica di Mukacevo come chiave della riscoperta della propria spiritualità
}

La Chiesa Cattolica ha una vasta gamma dei riti Orientali ed Occidentali. Uno di questi sia il Rito Bizantino che durante gli secoli avesse avuto tante tradizioni liturgiche nelle varie Chiese Cattoliche ed anche Ortodosse. Rimanendo nel ambito della Chiesa Cattolica troviamo le varie Chiese Greco Cattoliche come la Chiesa Greco Cattolica Ucraina, Chiesa Greco Cattolica di Ungheria, Chiesa Greco Cattolica di Slovacchia ed anche l'Eparchia Rutena Sui Iuris di Mukacevo. Tutte queste Chiese hanno il rito bizantino come il loro "proto rito". Cioè, il Rito Bizantino ha tante varie tradizioni liturgiche locali che arricchiscono il rito stesso. Importante di capire, che una tradizione liturgica non crea ancora un nuovo rito intero, soltanto vuole dare una forma di spiritualità locale che appartiene ad una regione, ad una Chiesa locale. Nel nostro caso parleremo di Eparchia Greco Cattolica di Mukacevo e sulla tradizione liturgica di questa Eparchia Sui Iuris per 
scoprire la sua spiritualità e sopratutto il ruolo della tradizione liturgica nella sua spiritualità.

\section{Che tradizione liturgica ha l'Eparchia di Mukacevo?}

Per dare la risposta su questa domanda bisogna conoscere un può la storia del'Eparchia. Le origine del cristianesimo sul terreno dell'odierna Eparchia risalgono ai tempi di attività degli discepoli dei santi Cirillo e Metodio. Molto difficile trovare un anno proprio per il battesimo della gente sotto i Carpazi, ma si parla del periodo della seconda metà del IX secolo ${ }^{1}$. Certo che non tutti gli storici dividono questa teoria, ma come prova, esiste una opinione secondo cui "il vescovato di Mukacevo era uno dei sette vescovati fondati dal santo Metodio" ${ }^{\prime 2}$. Per questo, con grande sicurezza possiamo dire, che il cristianesimo nel Eparchia di Mukacevo ha le sue radici nel rito bizantino in tale forma che sia portata dai santi apostoli Cirilo e Metodio da Tessalonica. Il seguente sviluppo della storia del'Eparchia non sia molto chiara fino a XIV-XV secoli. Forse la grande scisma avvenuta nel 1054 pian-piano si è arrivata anche a questi terreni, ma nel 24 aprile 1646 con la Unione di Uzhorod l'Eparchia definitivamente si è tornata a piena unione con la Chiesa Cattolica 3 . Una data molto importante sarebbe anche il 19 settembre del 1771 quando il Papa Clemente XIV con la bulla Eximia Regalium Principum ufficialmente ha proclamato l'Eparchia di Mukacevo ${ }^{4}$. Nonostante che dal punto di vista storica e giuridica c'erano molti cambiamenti e periodi scuri, però in livello liturgico possiamo avere tante verifiche che sul territorio del'Eparchia di Mukacevo esistevano sempre usanze liturgiche proprie ed irrepetibili. Uno di queste usanze siano le melodie liturgiche usate fino ad oggi che sono un "biglietto di visita" del Eparchia. Allora, per dare la risposta alla domanda "che tradizione liturgica ha l'Eparchia di Mukacevo?" possiamo rispondere, che l'Eparchia ha una tradizione

1 Vedi: А. Пекар, Нариси Історії Церкви Закарпаття, Т. 1, Рим-Аьвів 1997, р. 15.

2 “Traduzione del autore”. A. Hodinka, A Munkácsi görög-katholikus püspökség története, Budapest 1910, p. 59.

3 Vedi: А. Пекар, Нариси Історії Церкви Закарпаття, Т. 1, Рим-Аьвів 1997, р. 26.

4 Vedi: А. Пекар, Нариси Історії Церкви Закарпаття, Т. 1, Рим-Аьвів 1997, р. 65. 
liturgica con vari elementi che rispecchiano diversi periodi della sua storia. Cosi, per scoprire e rinnovare la propria tradizione liturgica del Eparchia Greco Cattolica di Mukacevo bisogna avere grande saggezza e non essere estremamente ne Orientali ne Occidentali. Cioè, Io dico sempre, che bisogna essere Greco Cattolici in quel senso in cui lo siano i fedeli del'Eparchia. In effetti gli fedeli stessi, la loro vita liturgica sono le prove più importante per scoprire la spiritualità del'Eparchia che si basa sulla sua tradizione liturgica. Cosa significa tutto questo?

\section{Il legame tra tradizione liturgica e spiritualità}

In sopradetto abbiamo chiarito cosa sia la tradizione liturgica. Adesso bisogna chiarire, cosa sia la spiritualità e che legame esiste tra loro? La spiritualità è qualcosa che ha da fare con lo spirito, con l'anima. Possiamo parlare sulla spiritualità come uno stato del anima umana, come una forma di vita sottoposta alle norme morali di un certo insegnamento. Cioè, esistono varie forme della spiritualità uno di cui la spiritualità cristiana. Parlando sulla spiritualità cristiana bisogna capire, che in senso generico si tratta delle norme della vita secondo la Bibbia e tutto il Magistero della Chiesa. Pero si può ancora ridurre il senso della parola spiritualità. Per esempio possiamo parlare sulla spiritualità cristiana cattolica e cosi posiamo arrivare fino ad una certa stretta categoria che si chiamasse la spiritualità dell'Eparchia di Mukacevo. La riduzione dipende sempre da quel elementi che formano la base di una certa spiritualità. Allora, un pilastro importantissimo della spiritualità di una certa Chiesa Sui Iuris sia la sua tradizione liturgica che forma il modo di vivere il cristianesimo in contesto di certe circostanze. La tradizione liturgica non cambia nessuna norma morale o Ecclesiale soltanto aiuta di capire meglio e mettere queste norme in azione nella vita quotidiana. Per esempio, una norma morale è che bisogna essere misericordiosi. Ma si pone la domanda, come essere misericordiosi nella vita quotidiana? Ecco, nelle varie celebrazione e preghiere troviamo la risposta, nelle varie testi liturgici abbiamo davanti le nostri occhi gli esempi della misericordia dei santi e cosi sappiamo come essere misericordiosi nella vita quotidiana. Le preghiere anche portano in se una vasta gamma della conoscenza di Dio, per esempio, quasi tutte le celebrazione nella parte del congedo contengono una molto intortante caratteristica di Dio, cioè, 
che Dio sia misericordioso ed amico degli uomini ${ }^{5}$. Se qualcuno queste parole ascolta ogni volta quando partecipa in una celebrazione nonostante nel suo cuore ed anima nascerà la speranza, che Dio perdonerà i suoi peccati. Cosi, le celebrazioni e le preghiere di un certo rito hanno il loro ruolo nella formazione di una certa spiritualità. Ecco la risposta, quale il legame tra tradizione liturgica e la spiritualità. Cosi, sulla spiritualità dell'Eparchia di Mukacevo certamente ha messa il suo timbro la sua tradizione liturgica.

\section{L'odierna tradizione liturgica del'Eparchia di Mukacevo}

La tradizione liturgica del'Eparchia si formava duranti gli secoli. Il periodo di cui abbiamo abbastanza informazione, e che ci interessa in prima fila, si comincia da Unione di Uzhorod, cioè dal 1646. Sicuramente in quel tempo esistevano alcune usanze ortodosse che dovevano essere cancellati o cambiati secondo la radizione cattolica. Il processo della pulizia del rito era una procedura molto lunga. Per esempio ancora nel 1751 il vescovo di Eger, Barkóczy Ferenc, scriveva, che nelle varie parrocchie del Eparchia di Mukacevo ancora si usano i libri ortodossi e per questo nelle celebrazione si mettono grandi sbagli. Per esempio, nelle ektenie e preghiere al posto di Re si nomina lo Czar ed al posto del Papa - il patriarca di Pietroburgo ${ }^{6}$.

Un altro tipo di problema si riferisce ai libri provenienti da Galicina, che da una parte erano già cattolici (perche l'unione di Brest aveva luogo 50 anni prima del unione di Uzhorod, cioè nel 1596) ma d'altra parte contenevano usanze proprie di un'altra Chiesa Greco Cattolica (odierna Chiesa Greco Cattolica Ucraina). Allora, siccome nel Eparchia di Mukacevo non erano ancora proprie libri liturgici cosi siano costretti comprare libri stampati a Leopoli, Pocaiv, Zovkva ect. Con questi libri nella propria tradizione liturgica d'Eparchia di Mukacevo pian piano si infilavano usanze stranieri. In seguito, nella fine del XIX secolo si comincia una seria delle prove del rinnovamento liturgico con la stampa dei propri libri liturgici e, sopratutto, si e stato composto nel 1880 il primo Typicon proprio di Eparchia di Mu-

5 Vedi: Anthologion, Roma 1999, p. 111.

6 Vedi: A. Hodinka, A Munkácsi görög-katholikus püspökség története, p. 798. 
$\mathrm{kacevo}^{7}$ - lavoro di dr. Alessandro Mikita, sacerdote del Eparchia e professore del seminario ${ }^{8}$. Lo sviluppo ed il chiarimento della propria tradizione durante il XX secolo non era una cosa molto facile, perche in periodo tra due Guerre Mondiali ed in seguito durante il regime comunista l'Eparchia non aveva ne forza ne modo di produrre libri ect. In quel tempo, cioè nella meta del XX secolo, a Roma si è sviluppato un processo del rinnovamento liturgico e ci sono stati stampati i libri liturgici cosiddetti Recensione Rutena. Per questo, dopo il 1989 quando l'Eparchia ha ricominciato di funzionare ufficialmente in livello liturgico esistevano da una parte le usanze stabilite prima del 1949 e d'altra parte si infilavano nuovi libri che contenevano una vasta gamma delle riforme e cambiamenti. Il clero che ha cominciato rinnovare la vita liturgica del'Eparchia èstato composto dai sacerdoti anziani che nella loro vita avevano una formazione basata sulla tradizione esistente prima di nascimento della Recensione Rutena. Per questo, nei primi 10-15 anni non si cambiava quasi niente. Poi, pian-piano si è venuta l'idea di fare il cambiamento dei libri liturgici prendendo quelli di Recensione Rutena come ideale. Con questo molte usanze proprie del'Eparchia siano spariti dalla pratica liturgica. Tutto questo si è posto una domanda fondamentale nella vita liturgica del'Eparchia - come procedere per non perdere la propria identità liturgica? Per essere sinceri, il periodo più adatto alla riscoperta della propria tradizione liturgica ed anche per la stampa dei propri libri liturgici si cade ai nostri tempi. I vescovi con sacerdoti devono fare forza per fare questo grande lavoro per il bene spirituale del popolo di Dio.

Per essere più concreto, l'odierna tradizione liturgica del'Eparchia potrei circoscrivere come una tradizione molto ricca di tradizione bizantina ma con certe elementi provenienti da altri tradizioni liturgiche. Penso, che non sia un problema avere influssi giusti e belli delle altre Chiese e tradizioni. Bisogna soltanto avere saggezza e sapere scegliere e distinguere tra quello che costruisce e quello che distrugge. Per esempio, l'odierna pratica liturgica non potrebbe essere neanche immaginata senza il Rosario o la Via Crucis. Anche in livello delle feste ci sono molto piacevoli le feste di Cristo Re, Corpus Domini, Il Sacro Cuore di Gesù. I fedeli si inginocchiano durante la Liturgia, amano pregare varie novenne ect. $\mathrm{Si}$, possiamo dire, che l'o-

7 Vedi: А. Микита, Руководство въ цеерковный типиконъ, Унгваръ 1901.

8 Vedi: А. Волошинъ, Мюсяцословь на 1911 годъ, Унгваръ 1910, р. 85-9о. 
dierna pratica liturgica è una miscela di quello che si chiamasse bizantino e latino. Ma questo non crea nessun problema se ne per alcuni sacerdoti ultra orientali o meglio dire Moscofili. Certo, che nella luce del II Concilio Vaticano bisogna tornare alle proprie radici, ma, secondo il mio parere, in questo processo non si può buttare via tutto che si è avvenuto nella vita liturgica durante gli secolo dopo l’Unione.

\section{Alcuni elementi della spiritualità del'Eparchia di Mukacevo}

\section{La Divina Liturgia}

La celebrazione più diffusa e amata dai fedeli è la Divina Liturgia. Cosi, la Liturgia possiede un posto privilegiato nella spiritualità popolare. Per questo motivo, la celebrazione della Liturgia in un certo senso forma la spiritualità. La partecipazione alla Liturgia è variabile. Alla Liturgia di domeniche e dei giorni festivi la quantità sia superiore come alle Liturgie feriali. Ma questo non è una novità. Pero interessante di parlare sul'orario delle celebrazioni. L'ore privilegiate per la celebrazione ci sono delle ore di mattina. Secondo alcuni, l'antica tradizione parla d'ora di mattina come l'unico periodo per la celebrazione della divina Liturgia. Nelle varie Chiese Ortodosse questa prattica non si amette nessun cambiamento. Ma nella tradizione della Chiesa Cattolica si è diffusa la pratica di celebrare la Divina Liturgia anche nelle ore sarali. Questa usanza si è avvenuta da motivi pratici, perche nei nostri tempi molti fedeli hanno tempo libero nelle ore della sera e per questo preferiscono questo tempo per partecipare alla Divina Liturgia. Ma questa usanza non va bene per tutti! Per una certa categoria dei fedeli, sopratutto per gli anziani, l'unica problema si riferisce alla comunione. Secondo loro, prima del comunione bisogna digiunare non soltanto una oretta, ma dalla sera. Cosi, se la Divina Liturgia si celebra alla sera, vengono alla celebrazione serale ma non tutti prendono la comunione. Cosi si vede, che la spiritualità dipendente dalla sacralità dell'Eucaristia sia divisa in due parti. Una spiritualità piuttosto rigorosa che il digiuno mette sopra la Grazia che porta la comunione, ed un'altra, che si concentra su tutti gli effetti che porta l'Eucaristia per quelli che lo ricevono.

L'altro tipo dei problemi nascono in livello delle rubriche. Per esempio, secondo le rubriche del Liturgicon ed anche secondo l'Ordo di celebrazione 
bisogna usare, o rinnovare l'usanza, di apertura e chiusura delle porte reale ed anche di catapetasma del iconostasi durante la Divina Liturgia9. Pero, nel Eparchia di Mukacevo dai antichi tempi le porte si rimassero aperte durante tutta la Divina Liturgia e la catapetasma non si usava. Allora, si pone la domanda, di lasciare questa usanza propria o cambiarla? Alcuni sacerdoti hanno messo la catapetasma e chiudono ed aprono la porta reale. Per alcuni fedeli questo significa una introduzione della pratica ortodossa e sia un scandalo, per gli altri - non importa. Nonostante possiamo notare, che la spiritualità della Divina Liturgia per i fedeli dipende molto di quello che si vede o non si vede. Se i fedeli non solo ascoltano ma anche vedono il sacerdote presente mi pare che la loro partecipazione alla Liturgia sia più viva perche il sacerdote rappresenta un ideale come bisogna comportarsi. È vero, questo potrebbe essere un esempio positivo o negativo, dipende dal sacerdote!

\section{La Liturgia delle Ore}

Una molto bella e profonda parte delle celebrazioni nel rito bizantino sia la Liturgia delle Ore. Una seria delle celebrazione dal Vespro fino l'Ora Nonna fa parte della spiritualità greco cattolica. Interessante da notare, che queste celebrazioni nelle chiese parrocchiale non vengono celebrati ogni giorno, soltanto il sabato sera e nei giorno prefestivi si celebra il Vespro, alla mattina di domenica o la festa si celebra l'Orthos. In molte parrocchie si celebra anche il Vespro alla sera di domenica e dei giorni festivi. Che si riferisce alla partecipazione del popolo di Dio, purtroppo possiamo notare una partecipazione molto diminuita al confronto della Divina Liturgia. A queste celebrazioni piuttosto vengono le persone anziani, invece gli giovani non pensano che sia importante partecipare, perché questo non è obbligatorio. Per questo motivo bisogna notare, che da parte dei sacerdoti manca tanto una spiegazione profonda della importanza e del significato di queste celebrazioni. Cosi, la Liturgia delle Ore ufficialmente fa parte della spiritualità popolare, ma non ha tanto influsso nella vita della maggioranza dei fedeli.

9 Vedi: Устав Богослужень, Рим 1958, р. 9-10. 


\section{Celebrazioni e preghiere popolari}

Interessante guardare come e che cosa pregano in maggior parte dei fedeli. Tra le preghiere popolare la più diffusa è il Rosario. Nel'Eparchia nelle molte parrocchie funzionano i cosiddetti "Comunità del vivo Rosario". Il compito di qualunque membro è pregare una parte del Rosario ogni giorno. Purtroppo la presenza degli maschi è molto bassa, piuttosto si tratta delle comunità femminile. Nonostante possiamo confermare, che questa preghiera rinforza tutta la comunità, il Rosario talvolta, sopratutto nel mese di Ottobre, si recita in comune prima della Divina Liturgia con la partecipazione non soltanto dei membri della "Comunità del vivo Rosario" ma con tutti i fedeli presenti. La spiritualità dei membri della "Comunità del vivo Rosario" rispecchia una spiritualità con la profonda venerazione della Madre di Dio.

Negli ultimi anni è stato popolarizzato la fondazione nelle varie parrocchie delle comunità "Madri in preghiera". La loro pratica di preghiera e composta di preghiere proprie della comunità ed anche qualche preghiere che esistono in rito del'Eparchia. Talvolta si notano anche momenti pericolosi dal punto di vista liturgica. Nella pratica di preghiera si vanno messi elementi strani. Per esempio, le donne che pregano si mettono in circuito attorno il tetrapod su cui sia posto il libro del Vangelo. Per questo nel Eparchia di Mukacevo il vescovo ufficialmente ha chiesto tutti i parroci di sorvegliare il funzionamento e la vita liturgica di queste comunità. La spiritualità di questa comunità si rispecchia un può una certa sopraelevazione, cioè i membri sono molto convinti che la loro preghiera sia la preghiera più forte che si esiste nel mondo.

Quasi 12 anni fa nel Eparchia di Mukacevo si è cominciato di funzionare anche il Cammino del Neocatecumenato. Nel aprile del 2015 il vescovo Milan Sasik ha fondato nel Eparchia anche il seminario missionario "Redemptoris Mater"10 che ufficialmente sia un seminario Neocatecumenale Greco Cattolico, ma in prattica non ha tanto ciò da fare con il rito bizatino e tradizione liturgica del'Eparchia di Mukacevo. Nelle loro pratiche liturgiche vedono un rinnovamento di qualche antiche tradizione cristiane, creano pratiche liturgiche non esistenti negando quello che è bello da se stesso. Per

10 “Циркуляр Мукачівської Греко-Католицької Єпрахії” 2015 № 51, р. 5. 
alcuni fedeli tutto questo è un vero scandalo. Pero, i seguaci del Cammino hanno una propria spiritualità che sia una nuova forma della spiritualità cristiana ed anche sia una innovazione per l'Eparchia di Mukacevo.

\section{Odierni problemi nel ambito della vita liturgica}

Da tutto sopradetto si viene fuori, che i problemi che riferiscono alla tradizione liturgica hanno il loro influsso nel ambito della spiritualità. Tutte quelle riforme liturgiche che ci hanno avuto posto nella vita del'Eparchia negli ultimi 30 anni cambiando la tradizione liturgica hanno cambiato la spiritualità del'Eparchia.

Alla base di maggior parte degli problemi liturgici nel'Eparchia ci stanno le varie tendenze liturgiche seguiti da vari sacerdoti. Da una parte possiamo notare, che purtroppo ancora non esistono libri liturgici propri in varie lingue per tutti gli nazionalità che comprende l'Eparchia. Per questo non si può ancora parlare su qualche obbligo di seguire certe prescrizioni, rubriche. Vero, in alcuni casi ci sono stabiliti le norme, ma anche queste norme a volta non sono seguiti fedelmente. Molto dipende proprio dal sacerdote, dalla sua mentalità ed anche dalle sue preferenze private. Per esempio, a volta succede, che a qualche sacerdote non piace la Via Crucis, il Rosario o la festa di Corpus Domini, allora, lo cancella dalla vita liturgica della parrocchia. Ad un altro sacerdote piace tanto l'adorazione Eucaristico, la celebrazione della Suplicazione - allora, lo fa regolarmente. A qualcuno non piace celebrare il Vespro o il Mattutino - allora, non gli celebra. E cosi possiamo notare tante cose che non vanno bene. Oltre di questo, nelle parrocchie ogni tanto si cambiano i sacerdoti. Per dire la verità, nel'Eparchia quasi non esistono parroci, in maggior parte ci sono amministratori delle parrocchie e come tali la loro permanenza non è per niente stabile. Io conosco parrocchie dove in circuito di otto anni ci sono cambiati cinque sacerdoti. Ed ognuno aveva il suo diciamo "profilo liturgico". Allora, i poveretti fedeli in questa parrocchia dovevano sempre adottarsi al sacerdote ed avere una vita liturgica molto colorata ed instabile. Questo significa, che la spiritualità della gente in questa parrocchia non poteva avere un stabile orientamento e crescenza. Proprio, non c'era una linea liturgica e spirituale per seguire. E questo, secondo me, crea un problema molto grave per la spiritualità. 


\section{Rinnovare la tradizione liturgica per scoprire la propria spiritualità}

Dopo aver elencato tanti problemi, bisogna cercare qualche soluzione per scoprire la propria spiritualità del'Eparchia. Secondo il mio parere, la chiave per la scoperta della propria spiritualità sia il rinnovamento della propria tradizione liturgica ed essere fedeli a tutte le prescrizioni da parte di tutti - vescovi, sacerdoti e fedeli. Allora, per primo bisogna fare un profondo studio storico-liturgico per circoscrivere tutto quello che fa parte della propria tradizione liturgica e cancellare tutto quello che va in confronto al tale tradizione. Poi è necessario formare un proprio Typikon per l'Eparchia sulla base del Typicon di Alessandro Mikita con certe aggiornamenti ed aggiunzioni. Durante questi studi bisogna prendere in considerazione due fonte fondamentali - i libri di Recensione Rutena ed i libri e prescrizioni nati durante gli secoli nel Eparchia di Mukacevo, sopratutto dopo l'Unione di Uzhorod.

La seconda tappa sarebbe più difficile, cioè mettere in vita reale tutte le proprie prescrizioni per formare una spiritualità unanima e propria. Non possiamo dimenticare le parole che ascoltiamo e proclamiamo ogni volta durante la Divina Liturgia:

E concedici di glorificare e di lodare con una sola voce e con un solo cuore l'onorabilissimo e magnifico tuo nome, Padre, Figlio e Spirito Santo, ora e sempre, e nei secoli dei secoli ${ }^{11}$.

Ecco, se non avessimo "una sola voce" nella vita liturgica, non potessimo avere neanche "un solo cuore" nella nostra spiritualità! Per questo bisogna pensarci non solo ai fedeli dell'Eparchia di lingua rutena, ma anche bisogna avere cura delle persone che pregano in ucraino, ungherese e romeno. Questo dovrebbe essere il compito più grande per l'Eparchia. Se non riusciamo rinnovare la tradizione liturgica, perdiamo la nostra propria spiritualità.

Per avere successo in rinnovazione della propria tradizione liturgica in ritrovamento della propria spiritualità nel Accademia Teologica di Uzhorod per i seminaristi si fanno varie corsi di liturgica secondo il programma

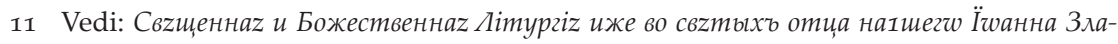
тоустаго, Римъ 1940, р. 76. 
prescritta. Durante le lezioni personalmente cerco di dare un incoraggiamento per scoprire la propria tradizione liturgica. Per questo provo di appoggiarsi massimamente sulle proprie libri, prescrizioni e tradizione orali.

Alla fine bisogna aggiungere, che tutto quello che è stato detto non si riferisce soltanto al'Eparchia di Mukacevo. Mi sono convinto, che anche nelle altre Chiese esistono questi o simili problemi. Come potrebbe esserci meglio al servizio della Tradizione? Molto semplice, - con il rinnovamento liturgico nello spirito della propria tradizione liturgica. La tradizione senza il rinnovamenti si invecchia e perde la sua bellezza negli occhi della gente. Invece i vari rinnovamenti o riforme che non prendono in considerazione la Tradizione si distruggono tutto quello che è stato costruito durante gli secoli. Sarebbe un pericolo grave di non dividere tra rinnovamento e riforma. Perche alcuni pensano, che rinnovare è uguale a riformare. Ma questo non è vero. La rinnovazione rida la vita a qualcosa che èra dimenticata o proprio buttata via. Invece la riforma ha per il suo scopo dare qualcosa nuovo al posto di vecchio facendo finta che sia qualcosa uguale. È come nel amore tra uomo e donna. Ogni tanto bisogna rinnovare il loro rapporto che a volta non significa nient'altro che ricordare e rinnovare alcuni belli momenti della loro vita comune. Ricordare il primo abbracciamento e il primo bacio, ricordare come era bello insieme per scoprire, che la persona che sta vicino a te non è un'altra persona ma è la stessa a cui sei stato innamorato. Forse il problema si trova in uomo stesso che pensa alla riforma al posto di rinnovamento. Come nella vita matrimoniale non ha posto un amante, cosi nella vita liturgica non ha posto niente che sta fuori della sua tradizione e spiritualità. Una celebrazione non si migliora con l'aggiunta, diciamo, della chitarra. La chitarra in questo caso sia come l'amante. Forse quel istrumento darà una nuova forma, ma non aiuta di capire meglio il significato della celebrazione. Invece se il sacerdote pian-piano comincia con le spiegazioni riscoprire il senso ed il significato di tutto quello che succede, la celebrazione comincerà di rinnovarsi anche senza qualunque cambiamento. Per questo bisogna tenere nella mente le parole che nella catechizazione la fonte ed il punto di partenza devono essere le proprie celebrazione liturgiche ${ }^{12}$.

12 Vedi: Інструкиія застосування літургійних приписів кодексу канонів Східних Церков, Пьвів 1996, р. 31-32. 
Ecco, alla fine bisogna confermare una verità: il rinnovamento della propria tradizione liturgica è la chiave della riscoperta della propria spiritualità. Questo vale sia per l'Eparchia di Mukacevo sia per qualunque altra Chiesa Sui Iuris. Spero, che Dio ci aiuterà di rinnovare sia la tradizione liturgica sia la spiritualità alla gloria del Padre ed il Figlio e dello Spirito Santo. Amen.

\section{Streszczenie}

Odnowa własnej tradycji liturgicznej w greckokatolickiej eparchii Mukaczewa jako klucz do odkrycia jej oryginalnej duchowości

Obrządek bizantyjski na przestrzeni wieków posiadał wiele tradycji liturgicznych, między innymi także tradycję liturgiczną rusińskiej diecezji (eparchii) sui iuris w Mukaczewie na Zakarpaciu. Ważne jest, aby zrozumieć, że tradycja liturgiczna nie tworzy tutaj jeszcze jednego zupełnie nowego obrządku, chce jedynie zaoferować formę lokalnej duchowości, charakterystycznej dla danego regionu, dla Kościoła lokalnego.

Początki chrześcijaństwa na terenie dzisiejszej diecezji Mukaczewa sięgają czasów działalności uczniów św. Cyryla i św. Metodego (druga połowa IX wieku). Mimo że z historycznego i prawnego punktu widzenia w jej dziejach było wiele zawirowań i ciemnych okresów, badanie życia liturgicznego eparchii mukaczewskiej dostarcza wielu dowodów, że na jej terenie zawsze istniały własne zwyczaje liturgiczne, trudne do odtworzenia. Można powiedzieć, że eparchia ma swoją tradycję liturgiczną z różnymi elementami, które odzwierciedlają różne okresy jej historii. Aby odkryć i odnowić własną tradycję liturgiczną greckokatolickiej diecezji w Mukaczewie, trzeba więc wykazać się wielką mądrością i nie podchodzić do niej ani z pozycji zbyt wschodniej, ani zbyt zachodniej (mamy tu na myśli tradycję liturgiczną).

Duchowość jest czymś, co ma związek z duchem, z duszą. Mówiąc o chrześcijańskiej duchowości, musimy zrozumieć, że w sensie ogólnym mamy do czynienia z normami życia zgodnie z Biblią i całym Magisterium Kościoła. Filarem duchowości danego Kościoła sui iuris jest jego tradycja liturgiczna, która kształtuje sposób życia chrześcijaństwa w kontekście pewnych okoliczności. Tradycja liturgiczna nie zmienia żadnych norm moralnych ani kościelnych, tylko pomaga lepiej zrozumieć i wprowadzić te normy w życie codzienne. Celebracje i modlitwy danego obrządku mają swoją rolę w formowaniu określonej duchowości. Oto odpowiedź, jaki jest związek między tradycją liturgiczną a duchowością. 
Dzisiejsza tradycja liturgiczna eparchii może być opisana jako bardzo bogata, należąca zasadniczo do tradycji bizantyjskiej, ale przyjmująca równocześnie elementy innych tradycji liturgicznych. Myślę, że słuszne i piękne wpływy pochodzące z innych Kościołów i tradycji nie stanowią większego problemu. Trzeba tylko mieć mądrość i umieć wybierać między tym, co buduje, a tym, co niszczy. Na przykład dzisiejszej praktyki liturgicznej nie można nawet sobie wyobrazić bez różańca lub drogi krzyżowej. Spośród świąt wierni bardzo upodobali sobie święta Chrystusa Króla, Bożego Ciała, Najświętszego Serca Jezusa. Wierni klęczą podczas liturgii, lubią odmawiać różne nowenny itd. Możemy powiedzieć, że dzisiejsza praktyka liturgiczna jest mieszanką tego, co nazwano „bizantyjskim” i „łacińskim”. To nie stanowi jednak problemu dla większości wiernych i duszpasterzy z wyjątkiem niektórych księży broniących czysto wschodniej tradycji, zwanych potocznie „moskofilami”.

Wszystkie reformy liturgiczne, które miały miejsce w życiu eparchii w ciągu ostatnich 30 lat zmieniających tradycję liturgiczna, zmieniły także jej duchowość. Wiele zależy właściwie od samego księdza, od jego mentalności, jak również od jego osobistych preferencji. Na przykład czasami zdarza się, że jakiemuś kapłanowi nie podoba się droga krzyżowa czy różaniec lub święto Bożego Ciała, dlatego eliminuje je z życia liturgicznego parafii. Innemu podobają się adoracja eucharystyczna, modlitwa błagalna - dlatego sprawuje je regularnie. Komuś nie podoba się odprawianie nieszporów lub jutrzni, więc ich nie celebruje. Możemy więc zauważyć, że wiele spraw z zakresu życia liturgicznego nie idzie dobrze. Poza tym kapłani zmieniają się dość często w parafiach. Znam parafie, w których pięciu kapłanów zmieniło się w przeciągu ośmiu lat. I każdy z nich miał swój „liturgiczny profil”. Dlatego wierni w tej parafii musieli się zawsze dostosować do takiego "urozmaiconego" życia liturgicznego. Oznacza to, że duchowość ludzi nie może się stabilnie rozwijać i wzrastać, nie ma bowiem stałego wzorca i linii do naśladowania. Taka sytuacja moim zdaniem stwarza bardzo poważny problem dla duchowości.

W mojej opinii kluczem do odkrycia własnej duchowości jest odnowienie własnej tradycji liturgicznej i wierność jej przepisom ze strony wszystkich księży i wiernych. Najpierw należy przeprowadzić więc głębokie i solidne badania historyczno-liturgiczne, aby dokładnie opisać wszystko to, co jest częścią własnej tradycji liturgicznej, i wyeliminować wszystko to, co jest z nią sprzeczne. Następnie należałoby utworzyć własny typikon dla eparchii na podstawie typikonu Aleksandra Mikity z pewnymi aktualizacjami i dodatkami. Drugi etap byłby trudniejszy - należałoby wszystkie te przepisy liturgiczne wprowadzić w życie w celu uformowania jednomyślnej i własnej duchowości. 
